\title{
Designing Checking Kecepatan Angin, Arah Angin dan Suhu Udara Outdoor Bagi Atlet Pemula Panahan Berbasis Android
}

\author{
Timur Dali Purwanto', Syaril Rizal2, Sulaiman³ \\ 12Informatics Departement, Bina Darma University, Palembang, Indonesia \\ 3Electrical Engineering Departement, Bina Darma University, Palembang, Indonesia \\ Email: 1timur.dali.purwanto@binadarma.ac.id, 2syaril.rizal@binadarma.ac.id, \\ 3sulaiman@binadarma.ac.id
}

\begin{abstract}
Abstrak
Olah raga panahan merupakan salah satu olah raga yang memperhatikan kecepatan angin dalam permainnya terutama pada lapangan (outdoor). Pergerakan angin pada lapangan panahan idealnya adalah maksimal kurang dari $10 \mathrm{mph}(<5 \mathrm{~m} / \mathrm{s})$. jika angin terlalu kencang dan arah angin tidak diketahui maka anak panah tidak akan tepat pada sasaran. untuk itu, perlu alat pengukur kecepatan angin dan"arah angin agar dapat membantu atlet panahan pemula mengetahui kecepatan.angin dan posisi arah angin sehingga, para atlet pemula dapat belajar membidik sasaran dengan tepat. Bukan hanya kecepatan dan arah angin saja, mengetahui suhu udara dapat membantu para atlet pemula untuk lebih mengenal lingkungan permainan panahan. Dari hasil pengukuran dapat dikirim melalui media IOT yakni aplikasi blynk pada hanphone android. Sehingga dapat mempermudah para atlet pemula dapat belajar membidik sasaran panahan dengan tepat dan agar kedepannya terbiasa dalam pertandingan.
\end{abstract}

Kata Kunci: media IOT, android, checking

\section{PENDAHULUAN}

Olahraga panahan merupakan salah satu olahraga yang memperhatikan kecepatan angin dalam permainannya terutama pada lapangan outdoor. Menurut [1] angin dengan kecepatan rata-rata $15 \mathrm{mph}$ yang datang dari arah jam 1:00 atau jam 5:00 dapat menghasilkan setengah arus melenceng dari sasaran. Dengan demikian, kecepatan pergerakan angin pada lapangan panahan idealnya adalah maksimal kurang dari $10 \mathrm{mph}(<5 \mathrm{~m} / \mathrm{s})$. Jika angin terlalu kencang dan arah angin tidak diketahui maka anak panah tidak akan tepat pada sasaran. Untuk itu, perlu alat pengukur kecepatan angin dan arah angin agar dapat membantu atlet panahan pemula mengetahui kecepatan angin dan posisi arah angin sehingga, para atlet pemula dapat belajar membidik sasaran dengan tepat. Bukan hanya kecepatan dan arah angin saja, mengetahui suhu udara 
dapat membantu para atlet pemula untuk lebih mengenal lingkungan permainan panahan.

Alat ini akan memantau kecepatan angin, arah angin, dan suhu udara pada lapangan panahan secara real time. Data yang dihasilkan akan dikirimkan langsung ke aplikasi hp yang berbasis android, sehingga data tersebut dapat diketahui secara cepat dan continue. Pengukur ini akan dibuat dalam bentuk portable sehingga mudah diletakkan dimana saja pada lapangan panahan

\section{METODOLOGI}

Metode penelitian tindakan adalah metode penelitian yang digunakan untuk menguji, mengembangkan. Menemukan dan menciptakan tindakan baru, sehingga tindakan tersebut kalau diterapkan dalam pekerjaan, maka proses pelaksanaan kerja akan lebih mudah, lebih cepat, dan hasilnya lebih banyak dan berkualitas [2].

\subsection{Planning (Perencanaan)}

Perancangan (desain) ini di bagi menjadi dua bagian yaitu perancangan hadware dan perancangan software, rancangan hardware digunakan alat pengukut untuk kecepatan angin, arah angin, dan suhu udara pada lapangan panahan (outdoor). Sensor yang akan digunakan pada rangkaian meliputi sensor hall effect tipe 477AH, sensor kompas tipe GY271, dan sensor suhu tipe DHT11. Hasil pengukuran akan langsung dikirimkan ke aplikasi blynk di handphone android dengan wemos wifi module tipe esp2866 sebagai penghubungnya dengan mendapatkan alamat TCP/IP. Berikut ini tampilan dari desai rangkaian alat.

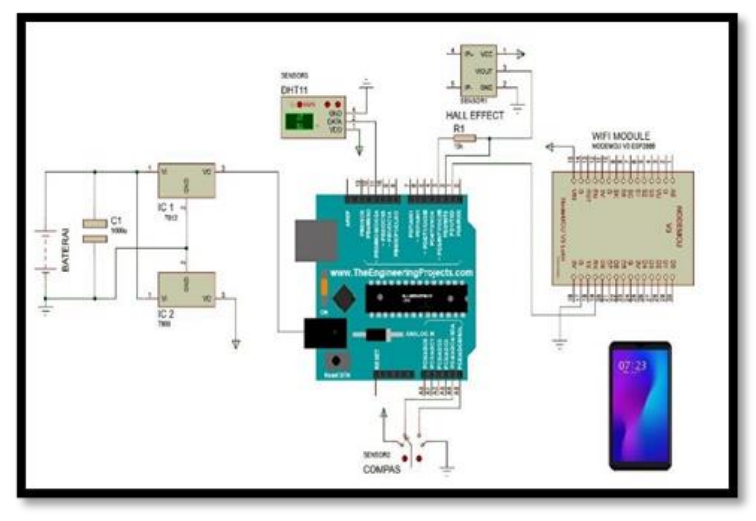

Gambar 1. Desain rangkaian keseluruhan 


\section{Journal of Information Technology Ampera \\ Vol. 2, No. 1, 2021 e-ISSN: 2774-2121}

https://journal-computing.org/index.php/journal-ita/index

Perancangan software, Sistem monitoring kecepatan angin, arah angin, suhu dan kelembaban udara berbasis media IOT memudahkan membuat aplikasi tanpa harus coding hanya menggunakan system drag dan logika, data hasil pengukuran dapat ditampilkan dalam bentuk angka di aplikasi android. Rangkaian terlebih dahulu dapat disimulasikan menggunakan aplikasi Proteus sehingga dapat dipastikan bahwa rangkaian yang akan dirangkai adalah benar serta dapat mengurangi kesalahan yang mungkin terjadi. Untuk menghasilkan output berupa tampilan akhir dibutuhkan sebuah aplikasi android untuk menciptakan aplikasi perangkat lunak bagi system operasi di android khususnya, maka disini penulis menggunakan Blynk App. Tampilan awal project dari Blynk App dapat dilihat pada gambar 2.

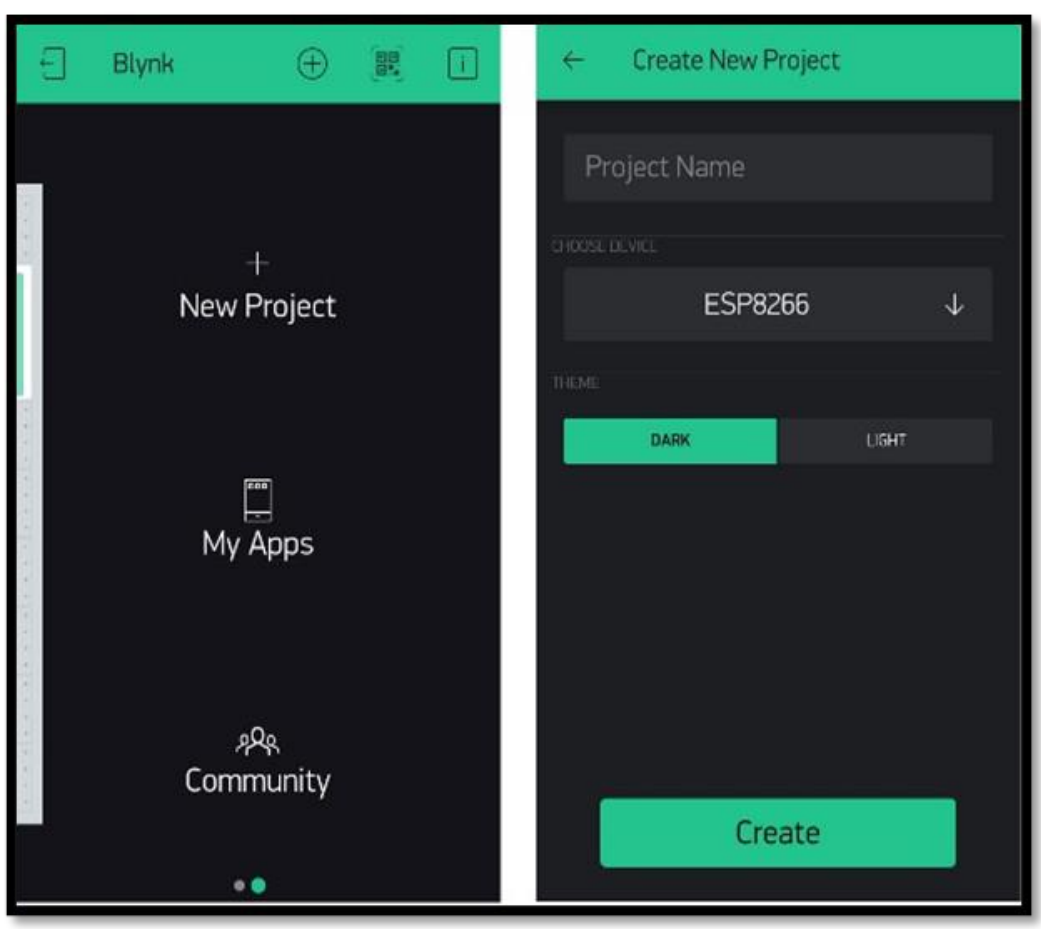

Gambar 2. Tampilan Blynk App.

Menu widget box digunakan untuk mengatur tampilan halaman project yang diinginkan. Terdapat beberapa pilihan tools yakni controllers, displays, notifications, device management, interface, smartphone sensors, dan tools other. Sebelum memilih perhatikan energy gratis yang diberikan yang terletak di awal. Setiap tools diberikan besaran energy. Jika masih memerlukan beberapa 
tools tetapi energi kurang, blynk memberikan pilihan untuk membeli energy tersebut. Selain itu, semua tools juga memiliki pengaturan-pengaturan untuk menyesuaikan tampilan dan fungsi sesuai keinginan.

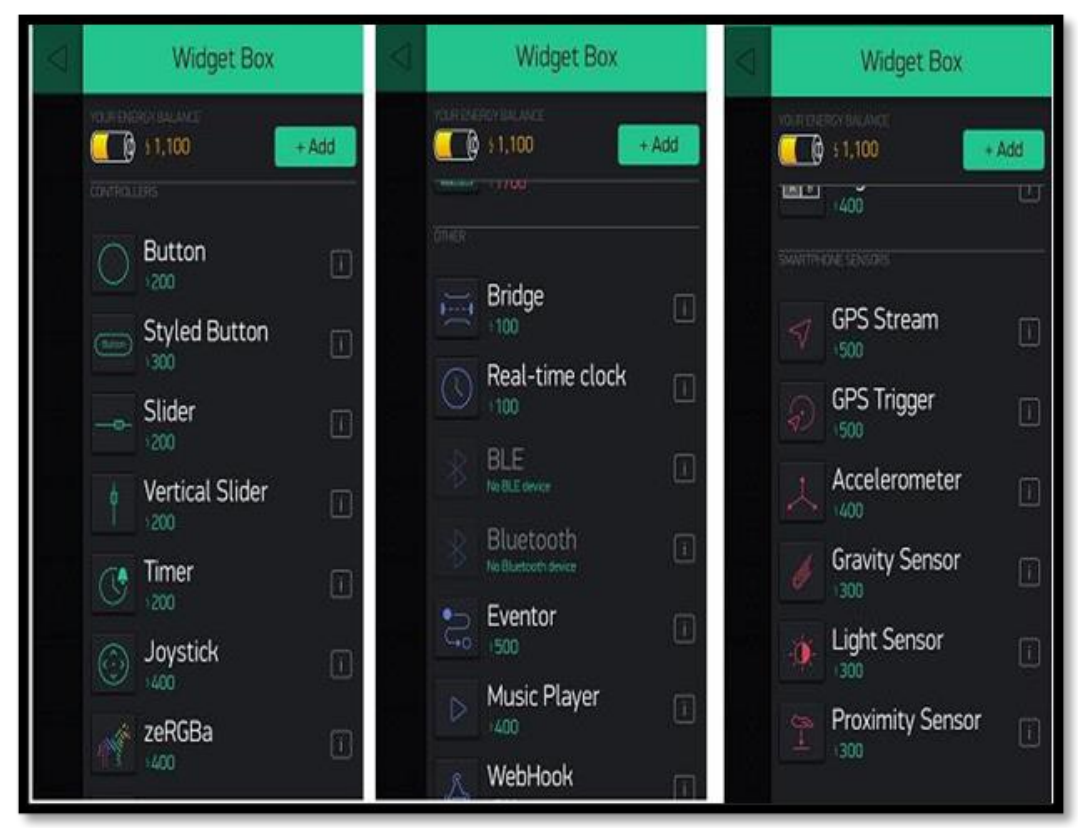

Gambar 3. Tampilan beberapa tools pada menu widget box

1. Tools Controler merupakan menu untuk memilih beberapa style kontrol yang diinginkan. Di menu ini terdapat pilihan button, styled button, slider, vertical slider, timer, joystick, zeRGBa, step H, dan Step V

2. Tools Display merupakan menu untuk memilih beberapa tampilan untuk hasil pengukuran sesuai keinginan. Terdapat beberapa pilihan yakni value display, labeled display, LED, Gauge, LCD, SuperChart, Terminal, Video Streaming, Level H, Level V dan Image Gallery.

3. Tools Notification merupakan menu untuk memilih notifikasi hasil pengukuran yang terdiri dari pilihan twitter, notification, dan email.

4. Tools Device management terdiri dari device selector dan device tiles.

5. Tools Other terdiri dari bridge, real-time clock, BLE, bluetooth, eventor, music player, webhook, reports dan webpage button,

6. Tools Interface terdiri dari tabs, menu, table, time input, map, text input, numeric input dan segmented switch.

7. Tools Smartphone Sensors merupakan menu yang terdiri dri gps stream, gps trigger, accelerometer, gravity sensor, light sensor dan proximity sensor. 


\section{Journal of Information Technology Ampera \\ Vol. 2, No. 1, 2021 e-ISSN: 2774-2121}

https://journal-computing.org/index.php/journal-ita/index

\subsection{Taking action (mengambil tindakan)}

Pada fase ini dilakukan tindakan yaitu mengimplementasikan desain atau perancangan hardware dan software yang telah dibuat.

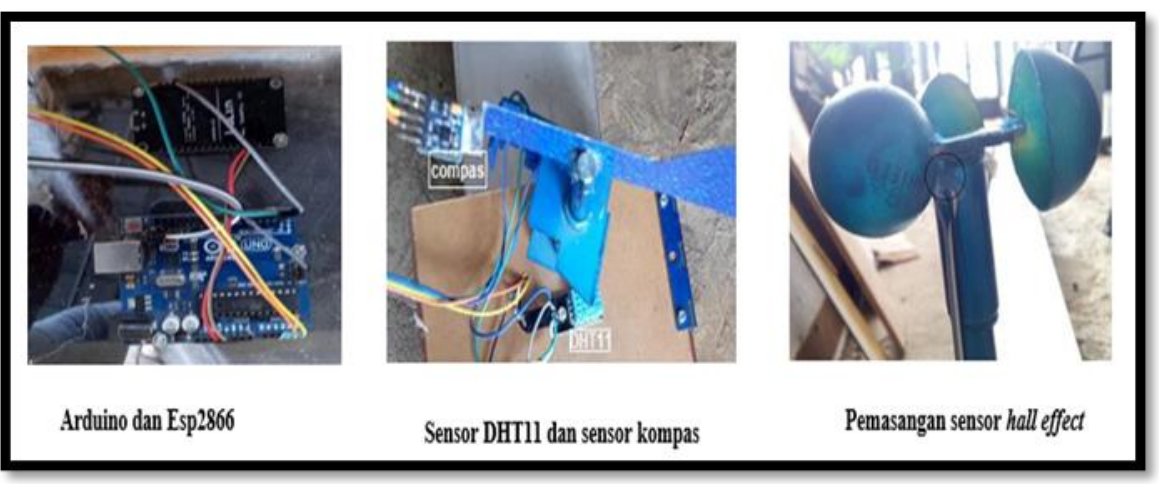

Gambar 4. Hasil Alat yang telah di rangkai

Pada "prototype pengukur kecepatan angin, arah angin dan suhu udara pada lapangan panahan berbasis iot" akan menggunakan beberapa sensor yakni sensor hall effect, sensor kompas, dan sensor DHT11. Untuk suplai utamanya menggunakan baterai. Adapun cara kerja alat ini adalah sebagai berikut: Saat aplikasi dinyalakan maka sistem akan berjalan. Ketika ada angin yang berhembus maka sensor hall effect akan mulai melakukan counter up atau perhitungan berapa banyak pulsa yang dihasilkan oleh baling-baling. Kemudian akan diteruskan ke arduino sebagai sinyal listrik, sinyal listrik tersebut akan diolah dan dilakukan kalibrasi satuan arah angin yaitu m/s. Lalu sensor kompas yang telah mendeteksi arah angin juga akan mengirimkan sinyal deteksian ke arduino. Begitu juga dengan sensor DHT11 yang telah berhasil mendeteksi suhu udara akan mengirimkan sinyal hasil deteksian ke arduino. Mikrokontroler arduino yang telah mengolah data akan meneruskan ke wemos wifi module. Wemos wifi module mendapatkan alamat TCP/IP kemudian mengirimkan hasil data tersebut ke aplikasi blynk di android. Di dalam aplikasi tersimpan history pengukuran. History pengukuran untuk arah angin akan disimpan dalam bentuk derjat azimut. Selama handphone terkoneksi internet, history pengukuran dapat dilihat. 
Journal of Information Technology Ampera

Vol. 2, No. 1, 2021 e-ISSN: 2774-2121

https://journal-computing.org/index.php/journal-ita/index
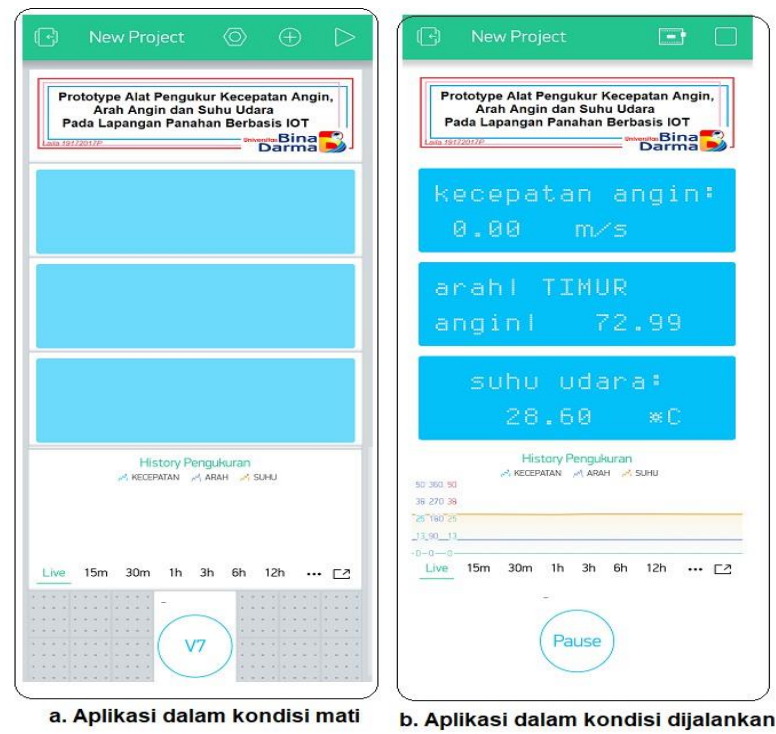

a. Aplikasi dalam kondisi mati

b. Aplikasi dalam kondisi dijalankan

Gambar 5. Hasil Software yang ada di android.

\section{HASIL DAN PEMBAHASAN}

Pada langkah metode penelitian ada Evaluasi atas tindakan dan seterusnya samapai dapat di temukan tindakan yang efektif dan efesien. Tindakan yang merujuk kepada efesien dilakukan pengujian yang terukur terhadap alat (hardware) pengukur yang telah dibuat. Alat harus diletakkan $50 \mathrm{~cm}$ dari tanah, jika diletakkan di tanah secara langsung angin tidak akan bias terukur dengan baik.

\subsection{Hasil}

Nilai pengukuran kecepatan angin dikirim langsung ke aplikasi blynk di android. Tampilan nilai pengukuran dapat di lihat pada gambar 6 .

\section{Kecepatan angin:}

9.80

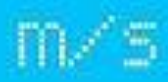

Gambar 6. Nilai pengukuran kecepatan angin 


\section{Journal of Information Technology Ampera}

Vol. 2, No. 1, 2021 e-ISSN: 2774-2121

https://journal-computing.org/index.php/journal-ita/index

Hasil dari pengujian pengukuran dapat dilihat dari tabel 1.

Tabel 1 Hasil pengujian pengukuran kecepatan angin

\begin{tabular}{|l|l|l|}
\hline No & Waktu & $\begin{array}{l}\text { Kecepatan } \\
\text { Angin }(\mathrm{m} / \mathrm{s})\end{array}$ \\
\hline 1 & $16: 43: 28$ & 9 \\
\hline 2 & $16: 43: 35$ & 5 \\
\hline 3 & $16: 43: 42$ & 2 \\
\hline 4 & $16: 43: 48$ & 6 \\
\hline 5 & $16: 43: 55$ & 0 \\
\hline 6 & $16: 44: 02$ & 0 \\
\hline 7 & $16: 44: 08$ & 13 \\
\hline 8 & $16: 44: 15$ & 9 \\
\hline 9 & $16: 44: 22$ & 5 \\
\hline 10 & $16: 44: 28$ & 0 \\
\hline
\end{tabular}

Grafik pengukuran dari tabel 1 yang juga dapat dilihat pada aplikasi blynk di android sebagai berikut.

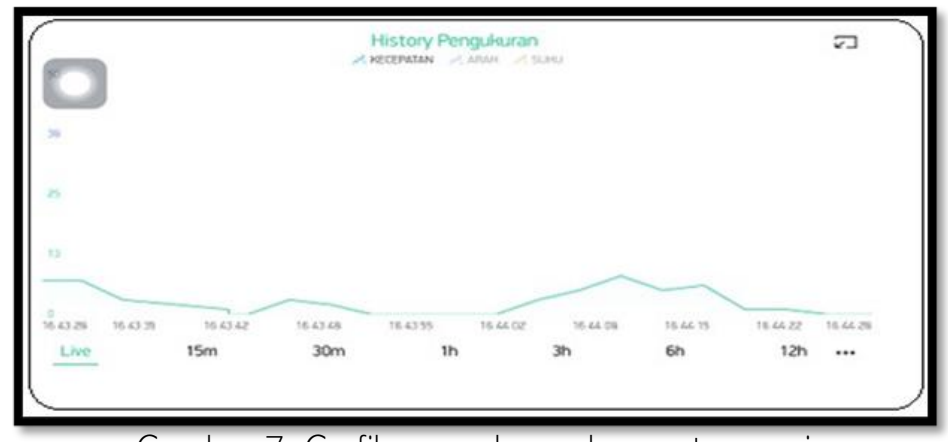

Gambar 7. Grafik pengukuran kecepatan angin

Nilai pengukuran arah angin dikirim langsung ke aplikasi blynk di android.

Tampilan nilai pengukuran

\section{$m m i n$ TIMUR}

\section{anint in 9.45}

Gambar 8 Nilai pengukuran arah angin 
Hasil dari pengujian pengukuran dapat dilihat dari tabel berikut ini :

Tabel 2 Hasil pengujian pengukuran arah angin

\begin{tabular}{|l|l|l|l|l|}
\hline No & Waktu & $\begin{array}{l}\text { Arah Mata } \\
\text { Angin }\end{array}$ & $\begin{array}{l}\text { Besar } \\
\text { Sudut }\end{array}$ & t range sudut \\
\hline 1 & $16: 43: 31$ & Tenggara & 112,17 & Akurat \\
\hline 2 & $16: 43: 38$ & Tenggara & 112,45 & Akurat \\
\hline 3 & $16: 43: 45$ & Tenggara & 113 & Akurat \\
\hline 4 & $16: 43: 51$ & Timur & 95,45 & Akurat \\
\hline 5 & $16: 43: 58$ & Timur & 96,32 & Akurat \\
\hline 6 & $16: 44: 05$ & Timur & 100,02 & Akurat \\
\hline 7 & $16: 44: 11$ & Timur & 102,34 & Akurat \\
\hline 8 & $16: 44: 18$ & Timur & 102,45 & Akurat \\
\hline 9 & $16: 44: 25$ & Timur & 102,36 & Akurat \\
\hline 10 & $16: 44: 31$ & Timur & 1002,37 & Akurat \\
\hline
\end{tabular}

Dari tabel 2 diketahui bahwa range sudut pengukuran arah angin sudah akurat sesuai dengan nama arah mata angin. Range besar sudut mata angin tersebut berdasarkan tabel 2. Grafik pengukuran dari tabel 2 yang juga dapat dilihat pada aplikasi blynk di android sebagai berikut.

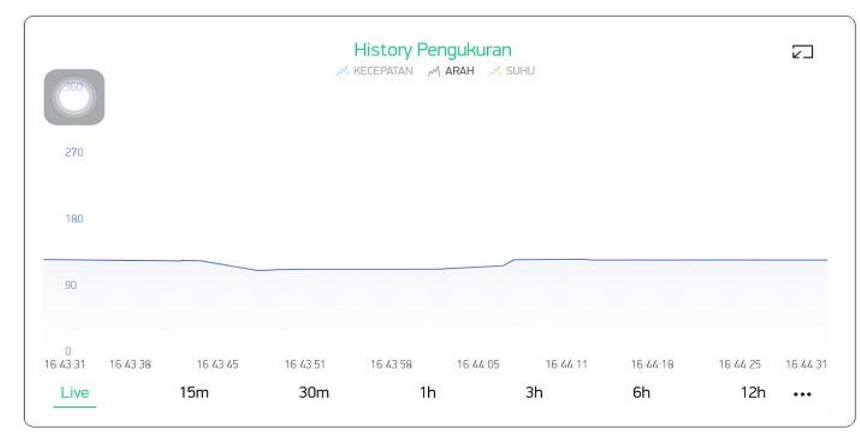

Gambar 9 Grafik pengukuran arah angin

Nilai pengukuran suhu udara dikirim langsung ke aplikasi blynk di android.

Tampilan nilai pengukuran dapat di lihat pada gambar 10 .

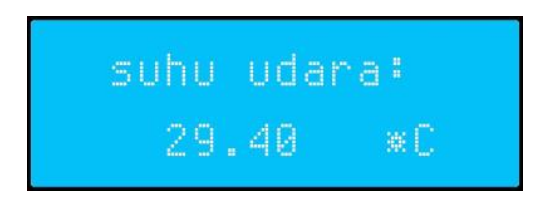

Gambar 10 Nilai pengukuran suhu udara 


\section{Journal of Information Technology Ampera}

Vol. 2, No. 1, 2021 e-ISSN: 2774-2121

https://journal-computing.org/index.php/journal-ita/index

Hasil dari pengujian pengukuran dapat dilihat dari tabel 3 berikut:

Tabel 3 Hasil pengujian pengukuran suhu udara
\begin{tabular}{|l|l|l|}
\hline No & Waktu & Suhu Udara \\
\hline 1 & $16: 43: 37$ & 29,40 \\
\hline 2 & $16: 43: 44$ & 29,40 \\
\hline 3 & $16: 43: 51$ & 29,40 \\
\hline 4 & $16: 43: 57$ & 29,40 \\
\hline 5 & $16: 44: 04$ & 29,40 \\
\hline 6 & $16: 44: 11$ & 29,40 \\
\hline 7 & $16: 44: 17$ & 29,40 \\
\hline 8 & $16: 44: 24$ & 29,40 \\
\hline 9 & $16: 44: 31$ & 29,40 \\
\hline 10 & $16: 44: 37$ & 29,40 \\
\hline
\end{tabular}

Grafik pengukuran dari tabel 3 yang juga dapat dilihat pada aplikasi blynk di android sebagai berikut.

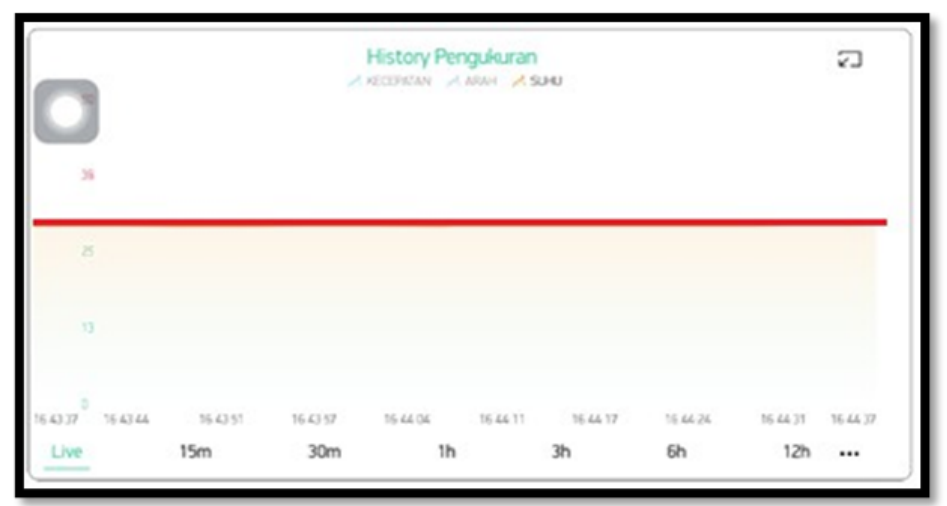

Gambar 11 Grafik pengukuran suhu udara

1. Dari hasil pengukuran rancang bangun alat ini didapati hasil yang cukup baik karena persentase kesalahannya berada dibawah $5 \%$.

2. Pada sensor hall effect jika tidak ada angin dan ketika ada angin akan ada perbedaan tegangan. Perbedaan ini diakibatkan karena hall effect menggunakan sistem counting yang menyebabkan tegangan akan turun jika adanya pengukuran. 
3. Untuk hasil pengujian pengukuran arah angin didapatkan hasil tertinggi pengukuran sebesar $13 \mathrm{~m} / \mathrm{s}$. [3]Dimana batas angin yang dianjurkan untuk aktivitas panahan kurang dari $5 \mathrm{~m} / \mathrm{s}$. Ini berarti hasil pengukuran sebesar ini dapat mengakibatkan anak panah melenceng dari sasaran.

4. Untuk pengukuran arah angin, selain menggunakan nama mata angin juga menggunakan range besar sudut. Range besar sudut berguna untuk mendapatkan nama arah mata angin. Jika tidak menggunakan range besar sudut, nama mata angin tidak bisa ditampilkan secara akurat di aplikasi android.

5. Pengukuran suhu didapatkan pengukuran yang stabil sebesar $29,40^{\circ} \mathrm{C}$. Suhu yang dianjurkan untuk aktivitas outdoor [4] sebesar $27-30^{\circ} \mathrm{C}$. Ini berarti hasil simulasi pengujian dapat dikategorikan sebagai suhu yang nyaman untuk beraktivitas di outdoor terutama untuk aktivitas memanah.

\section{KESIMPULAN}

Semua kinerja pada perancangan alat (hardware) dan software dapat berjalan dengan baik dalam penggunaanya media IOT pada aplikasi blynk di handphone android terkoneksi dengan baik. Dapat dilihat dari hasil analisis pengukuran arah angin yang mempunyai pengukuran maksimum $13 \mathrm{~m} / \mathrm{s}$, dan minimum $2 \mathrm{~m} / \mathrm{s}$. ini yang berarti hasil pengukuran maksimum yang dapat mengakibatkan anak panah melenceng dari sasaran.

DAFTAR PUSTAKA

[1] D. S. Nugraha and T. Isfiaty, "Modernisasi Interior Fasilitas Panahan Bergaya Morocco Dengan Konsep Arrow Point," vol. 3, pp. 237-243, 2017.

[2] Sugiono, "Metode Penelitian Tindakan (Action Research)," Pros. Semin. Nas. Jur. PGSD FIP UNP Tahun 2015, vol. vol 1, no. 2015, pp. 1-120, 2015.

[3] R. Prabowo, A. Muid, and R. Adriat, "Rancang Bangun Alat Pengukur Kecepatan Angin Berbasis Mikrokontroler ATMega 328P," Tek. Elektro, vol. VI, no. 2, pp. 94-100, 2018, doi: https://dx.doi.org/10.26418/pf.v6i2.25260.

[4] Herdianto, "Perancangan Smart Home dengan Konsep Internet of Things ( loT ) Berbasis Smartphone," I/m. Core It, vol. 6, no. x, pp. 120-130, 2018. 